\title{
Article \\ Effect of Baking Temperature on the Phenolic Content and Antioxidant Activity of Black Corn (Zea mays L.) Bread
}

\author{
Gracia Patricia Blanch and Maria Luisa Ruiz del Castillo *
}

check for

updates

Citation: Blanch, G.P.; Ruiz del

Castillo, M.L. Effect of Baking

Temperature on the Phenolic Content

and Antioxidant Activity of Black

Corn (Zea mays L.) Bread. Foods 2021,

10, 1202. https://doi.org/10.3390/

foods10061202

Academic Editors:

Antonella Pasqualone and

Mike Sissons

Received: 19 April 2021

Accepted: 25 May 2021

Published: 26 May 2021

Publisher's Note: MDPI stays neutral with regard to jurisdictional claims in published maps and institutional affiliations.

Copyright: (c) 2021 by the authors. Licensee MDPI, Basel, Switzerland. This article is an open access article distributed under the terms and conditions of the Creative Commons Attribution (CC BY) license (https:// creativecommons.org/licenses/by/ $4.0 /)$
Instituto de Ciencia y Tecnología de Alimentos y Nutrición, Consejo Superior de Investigaciones Científicas (ICTAN-CSIC), Juan de la Cierva 3, 28006 Madrid, Spain; gblanch@ictan.csic.es

* Correspondence: mruiz@ictan.csic.es

Abstract: Black corn is known for its health-promoting properties, which are due to its high content of bioactive phytonutrients. However, the high temperatures required during the processing of bakery products usually trigger thermal degradation, and therefore, the loss of all labile bioactive compounds. In the present study, we evaluated the effect of baking temperature on the phenolic content (i.e., TPC, TAC and individual phenolics) and antioxidant activity in black corn (Millo corvo variety) bread. As a result, baking always resulted in a general decrease in TPC, even at $150{ }^{\circ} \mathrm{C}$. In contrast, TAC only decreased when temperatures as high as $180^{\circ} \mathrm{C}$ were applied. Some relevant individual phenolics were preserved during the whole process as long as $150^{\circ} \mathrm{C}$ was used. In particular, the content of the major anthocyanin, namely, cyanidin-3-O-glucoside, hardly decreased from the raw flour to the final bread. The loss of antioxidant activity of Millo corvo raw flour during bread baking was avoided by heating at $150{ }^{\circ} \mathrm{C}$. These results demonstrate the appropriate temperature to bake Millo corvo corn bread without losing the antioxidant characteristics and health-promoting properties of the starting black corn.

Keywords: Millo corvo; black corn; phenolics; antioxidant activity; bread; heating

\section{Introduction}

Corn, together with rice, is one of the most cultivated cereals in the world, and since it is gluten-free, it is also suitable for consumption by those with celiac disease. There are several varieties of corn; however, in recent years, black corn has become particularly popular. From a marker standpoint, black corn is a natural colorant with a plant origin that can be very interesting as an alternative to artificial additives. More importantly, black corn possesses excellent nutritional properties due to its high content of relevant phytonutrients with functional roles in human health [1].

In this respect, black corn contains some phenolics, carotenoids and particularly high content of anthocyanins [2]. Summing up the results of many studies, anthocyanins possess anticarcinogenic activity, cardiovascular disease prevention, obesity control and diabetes alleviation properties [3]. Among the anthocyanins reported in black corn, cyanidin-3-Oglucoside is the most abundant [4]. Beneficial health-related effects of non-anthocyanin phenolic compounds (e.g., quercetin, kaempferol, phenolic acids) that are present in black corn have also been extensively reported [5].

Corn-based foods require a thermal process prior to consumption. In this context, the inadequate selection of baking time and temperature may cause breakdown problems, such as cracking and checking [6], affecting the final quality [7]. The baking conditions may also bring about the degradation of thermally unstable compounds, such as anthocyanins [7]. In fact, many processed food containing anthocyanins exhibited a decrease in their content as a result of the thermal treatment [8]. The goal of this research was to evaluate the effect of baking temperature on the content of phenolic compounds in general and on anthocyanins in particular, as well as on the antioxidant activity of bread baked using black corn (Millo corvo variety). To this end, the phenolic composition and antioxidant properties of the 
final bread obtained were compared with those of the starting Millo corvo flour to select the heating conditions that enabled the flour antioxidant content to be preserved. To date, no bibliographic report can be found in the literature about bakery products baked using Millo corvo corn.

\section{Materials and Methods}

\subsection{Chemicals}

Ultrapure water was obtained from a purification system (Millipore Milford, MA, USA). Both formic acid and $\mathrm{MeOH}$ (HPLC grade) were obtained from VWR Inc. (Bridgeport, PA, USA). 2,2-diphenyl-2-picrylhydrazil (DPPH) and sodium carbonate standards were supplied by Sigma-Aldrich (Steinheim, Germany). An antioxidant capacity lipidsoluble (ACL) kit was acquired from Sigma-Aldrich (Steinheim, Germany). Foulin-Ciocalteu reagent was obtained from Merck (Darmstadt, Germany). Chlorogenic, caffeic and ferulic acids, as well as quercetin and quercertin-3-glucoside standards, were purchased from Sigma-Aldrich (Steinheim, Germany). Cyanidin-3-O-glucoside standard was provided by Extrasynthase (Genay, France).

\subsection{Materials}

For the experiments, black corn (Zea mays L., Millo corvo variety) and conventional white corn produced and supplied by Asociación Cultural Meiro (Morrazo, Pontevedra, Spain) were used. Flour samples were prepared via dekerneling corn by hand and then grinding the whole grain using a traditional stone corn mill. Flour samples were immediately stored at $-14{ }^{\circ} \mathrm{C}$ until their use. The preparation of bread was accomplished as follows: dough from flour was carried out by mixing $35 \mathrm{~g}$ of raw flour with $10 \%$ of water. The mixture was then optimally hand kneaded to a smooth dough. The breadmaking process was performed in a scale-down method by adding $4.6 \mathrm{~g}$ of fresh yeast to $35 \mathrm{~g}$ of the dough previously prepared. After that, it was kneaded by hand up to a homogenous mixture, which was finally baked in an oven at $150{ }^{\circ} \mathrm{C}$ for $60 \mathrm{~min}$. Two batches were run for each sample.

\subsection{Extraction}

For the experiments, a $5 \mathrm{~g}$ sample weight was used. Polyphenols were extracted by adding $60 \mathrm{~mL}$ of solvent methanol/acetone/water (35/35/30) to the sample. The resulting mixture was homogenised with an Ultraturrax homogeniser (IKA, Sigma-Aldrich, Madrid, Spain) for $10 \mathrm{~min}$ and then centrifuged at $2500 \mathrm{rpm}$ at $15{ }^{\circ} \mathrm{C}$ for another $10 \mathrm{~min}$. The solvent was removed and an additional $6 \mathrm{~mL}$ of methanol/acetone/water (35/35/30) was added to the extract, which was re-extracted. Then, the extract was taken to dryness using a rotary evaporator. Finally, the dry extract was stored at $-14{ }^{\circ} \mathrm{C}$ until analysis. The extractions were carried out in triplicate and both the Millo corvo flour and bread samples were analyzed as explained below.

\subsection{Total Phenol Content (TPC)}

The equipment used for TPC measurements was a Beckman Coulter DU-800 spectrophotometer (Barcelona, Spain). The method applied was based on the oxidation of the hydroxyl groups of phenols in basic media by the Folin-Ciocalteu reagent, as described in the literature [9]. In brief, $0.5 \mathrm{~mL}$ of Folin-Ciocalteu reagent and $10 \mathrm{~mL}$ of a sodium carbonate solution $\left(75 \mathrm{~g} \mathrm{~L}^{-1}\right)$ were added to a $0.1 \mathrm{~mL}$ volume of the extract $\left(20 \mathrm{mg} \mathrm{mL}^{-1}\right)$. The final mixture was made up to $25 \mathrm{~mL}$ with distilled water. After $1 \mathrm{~h}$, the absorbance was measured at $750 \mathrm{~nm}$ against a blank (i.e., mixture without the reagent). The results were expressed as milligrams of gallic acid equivalents (GAE) per $100 \mathrm{~g}$ of sample. All the analyses were carried out in triplicate. 


\subsection{Total Anthocyanin Content (TAC)}

Total anthocyanin was quantified using the $\mathrm{pH}$ differential method reported elsewhere [10]. Millo corvo corn flour and bread samples were diluted with $0.025 \mathrm{M}$ potassium chloride buffer solutions at $\mathrm{pH} 1$ and with $0.4 \mathrm{M}$ sodium acetate buffer at $\mathrm{pH} 4.5$. A 400-700 nm sweep was carried out using a spectrophotometer (Beckman Coulter DU-800 spectrophotometer, Barcelona, Spain). TAC was expressed as milligrams of cyanidin-3$O$-glucoside equivalents per $100 \mathrm{~g}$ of sample based on a molar extinction coefficient of $26,900 \mathrm{~L} \mathrm{~cm}^{-1}$ and a molecular weight of $449.4 \mathrm{~g} / \mathrm{L}$.

Total absorbance was measured using the equation:

$$
\mathrm{Abs}_{\mathrm{t}}=\left(\mathrm{Abs}_{520 \mathrm{~nm}}-\mathrm{Abs}_{700 \mathrm{~nm}}\right)_{\mathrm{pH}=1}-\left(\mathrm{Abs}_{520 \mathrm{~nm}}-\mathrm{Abs}_{700 \mathrm{~nm}}\right)_{\mathrm{pH}}=4.5
$$

\subsection{DPPH Activity}

Antioxidant activity was determined using a $\mathrm{DPPH}^{*}$ assay [11] with slight modifications. The same equipment as that described for the TPC and TAC was used. The extracts were dissolved in methanol to prepare a stock solution of $20 \mathrm{mg} \mathrm{mL}^{-1}$. This solution was further diluted to final concentrations of 15.6, 62.5, 125, 250 and $500 \mu \mathrm{g} \mathrm{mL}^{-1}$ before being transferred to a 96-well microtiter plate. Before adding $\mathrm{DPPH}^{*}$, each extraction solution was used as a blank. Each well contained $50 \mu \mathrm{L}$ aliquot of the sample and $150 \mu \mathrm{L}$ of DPPH $(400 \mu \mathrm{mol} \mathrm{L}-1)$. Each mixture was incubated at $37^{\circ} \mathrm{C}$ for $30 \mathrm{~min}$ and then the absorbance at $517 \mathrm{~nm}$ was monitored. The absorbance value obtained was compared with that of the $\mathrm{DPPH}^{*}$ solution measured immediately after being prepared, which was used as a reference. The absorbance decrease obtained indicated the percentage inhibition of the $\mathrm{DPPH}^{*}$ by each dilution level of the samples. A plot of percentage inhibition versus concentration was made and the $\mathrm{IC}_{50}$ values were calculated using linear regression analysis. The experiments were performed in duplicate

\subsection{Photochemiluminiscence (PCL) Activity}

The antioxidant capacity was also determined using a PCL assay. This method was applied using a Photochem ${ }^{\circledR}$ device (Analytik Jena AG, Jena, Germany) and it was conducted via an ACL protocol, which allows for the antioxidant capacity of the lipidsoluble components to be measured [12]. The study was performed using a commercial reagent kit ACL (Analytik Jena AG, Jena, Germany) [13]. For the assays, the extract was first dissolved in methanol:water (70:30) (about $30 \mathrm{~g} \mathrm{~L}^{-1}$ ). A $20 \mu \mathrm{L}$ volume of this solution was then mixed with ACL reagent and the mixture was placed into the Photochem device. Results were calculated on the basis of standard curves into nanogram Trolox equivalents per microlitre of sample (ng $\left.\mu \mathrm{L}^{-1}\right)$.

\subsection{Content of Phenolic Compounds}

The content of individual phenolics was determined using HPLC. The equipment used for the measurements was an Alliance Separation Module 2695 chromatograph (Waters, Milford, CT, USA) with an automatic injector and a photodiode array detector 996 (DAD, Waters, Milford, CT, USA). The separation of the target compounds was accomplished on an ODS reverse phase $\left(C_{18}\right)$ column $(250 \mathrm{~mm} \times 4.6 \mathrm{~mm}$ i.d., particle size $5 \mu \mathrm{m}, \mathrm{ACE}$, Madrid, Spain) at a flow rate of $1 \mathrm{~mL} \mathrm{~min}{ }^{-1}$. To protect the column, an Altima $5 \mu \mathrm{m}$ $\mathrm{C}_{18}$ pre-column (Altech, Barcelona, Spain) was used. Both the pre-column and column operated at $20^{\circ} \mathrm{C}$. The elution program was the same as previously optimised [14]. Blanks between consecutive runs were performed. Phenolic acids were registered at $320 \mathrm{~nm}$, quercetin at $360 \mathrm{~nm}$, quercertin-3-glucoside at $348 \mathrm{~nm}$ and cyanidin-3-O-glucoside at $520 \mathrm{~nm}$. Stock solutions of the standard compounds were prepared in $70 \%(v / v)$ methanol to a final concentration of $1 \mathrm{mg} \mathrm{mL}^{-1}$. In addition, calibration curves of the standards were established for six data points and each standard dilution was run in triplicate. The extracts were also reconstituted in $700 \mathrm{~mL} \mathrm{~L}^{-1}$ methanol and also run three times at a concentration of $20 \mathrm{mg} \mathrm{mL}^{-1}$ for the quantification of polyphenols. 


\subsection{Statistical Analysis}

An analysis of variance for the TPC, TAC, DPPH and PCL activities and individual phenolic content was carried out using the one-way analysis of variance (ANOVA) method. The results are presented as the average of all values obtained and standard deviation ( $\mathrm{mg} \mathrm{kg}^{-1}$ weight $\pm \mathrm{SD}$ ). Data from raw flour, heated flour and bread were included in the statistical analysis. Comparisons of means were made by using Fisher's protected LSD. Differences were considered significant for $p<0.05$.

\section{Results and Discussion}

\subsection{Comparison between Millo corvo Corn Flour and White Corn Flour}

Initially, raw Millo corvo corn flour was compared with conventional white corn flour in terms of the TPC and antioxidant properties, which were measured using two different assays (i.e., DPPH and PCL). PCL is a relatively new method for measuring antioxidant capacity. It is based on the optical excitation UV sensitiser that causes free radical generation, which is partially eliminated by naturally occurring antioxidants in the sample [15]. The results are summarised in Table 1. As seen, significant $(p<0.05)$ differences between the two flours were measured. Millo corvo corn flour exhibited significantly $(p<0.05)$ higher TPC and antioxidant activity from both the DPPH and PCL methods. Different TPC data were reported according to the corn cultivar [1,16]. However, all bibliographic studies on antioxidant activity agree on the higher antioxidant capacity of colored corn with respect to that of white ones [1] due to the higher content of natural pigments, mainly anthocyanins.

In a view of these results, the use of white corn flour to bake bread was discarded. The bread study was only carried out using Millo Corvo corn flour as an ingredient.

Table 1. TPC (expressed as mg GAE $100 \mathrm{~g}^{-1}$ ) and antioxidant activity measured using DPPH (expressed as $\mathrm{IC}_{50}, \mu \mathrm{g} \mathrm{mL} \mathrm{m}^{-1}$ ) and PCL (ng Trolox $\mathrm{mL}^{-1}$ ) methods in white corn flour and Millo corvo corn flour.

\begin{tabular}{cccc}
\hline Sample & TPC & PCL & IC $_{\mathbf{5 0}}$ \\
\hline White corn flour & $169.7 \pm 0.12^{\mathrm{a}}$ & $331.9 \pm 0.09^{\mathrm{a}}$ & $2182.2 \pm 0.12^{\mathrm{a}}$ \\
Millo corvo corn flour & $305.3 \pm 0.15^{\mathrm{b}}$ & $734.3 \pm 0.15^{\mathrm{b}}$ & $1091.7 \pm 0.16^{\mathrm{b}}$ \\
\hline
\end{tabular}

Different letters in the same row indicate differences at $p<0.05$ between baking temperatures. Experiments were carried out in triplicate.

\subsection{Effect of Temperature on the Antioxidant Content in Millo corvo Flour}

The effect of temperature on TPC, TAC, DPPH scavenging activity and individual phenolics in raw Millo corvo flour was performed by reproducing the baking processing at 150,180 and $200{ }^{\circ} \mathrm{C}$.

As can be seen, the TPC values decreased significantly $(p<0.05)$ with heating. In particular, TPC dropped from $305.3 \mathrm{mg} \mathrm{GAE} 100 \mathrm{~g}^{-1}$ in the unheated flour samples to 119.6, 105.6 and $102.3 \mathrm{mg}$ GAE $100 \mathrm{~g}^{-1}$ after heating at $150^{\circ} \mathrm{C}, 180^{\circ} \mathrm{C}$ and $200{ }^{\circ} \mathrm{C}$, respectively. Interestingly, all the temperatures tested provided similar results.

Regarding TAC, values also diminished with heating. In particular, a significant $\left(p>0.05\right.$ ) decrease from $381 \mathrm{mg}$ cyanidin-3-O-glucoside $100 \mathrm{~g}^{-1}$ in the unheated sample to $27 \mathrm{mg}$ cyanidin-3-O-glucoside $100 \mathrm{~g}^{-1}$ after heating at $180^{\circ} \mathrm{C}$ was measured. The apparent changes observed after heating at $150{ }^{\circ} \mathrm{C}$ and $200{ }^{\circ} \mathrm{C}$ were not considered since they were not statistically significant.

Concerning the DPPH scavenging activity, a similar trend was observed (see Figure 1). The $\mathrm{IC}_{50}$ value obtained for unheated flour (i.e., $1091.7 \mu \mathrm{g} \mathrm{mL}{ }^{-1}$ ) was not significantly $(p>0.05)$ affected after heating at $150{ }^{\circ} \mathrm{C}$ (i.e., $943.9 \mu \mathrm{g} \mathrm{mL} \mathrm{L}^{-1}$ ). However, the application of $180{ }^{\circ} \mathrm{C}$ and $200^{\circ} \mathrm{C}$ during the baking process did result in a significant $(p<0.05)$ increase in $\mathrm{DPPH}$ activity, particularly at $200^{\circ} \mathrm{C}$ (i.e., $\mathrm{IC}_{50}$ value of $36.0 \mu \mathrm{g} \mathrm{mL}{ }^{-1}$ ). 


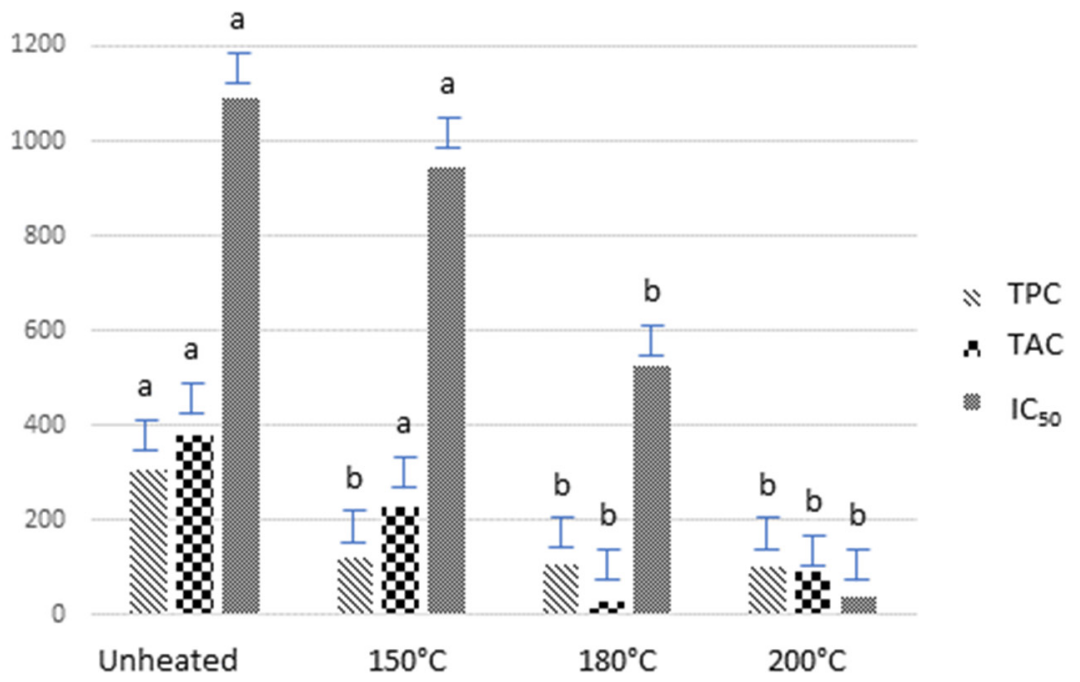

Figure 1. Depicts TPC (expressed as mg GAE $100 \mathrm{~g}^{-1}$ ), TAC (expressed as mg cyanidin-3-O-glucoside $100 \mathrm{~g}^{-1}$ ) and free radical scavenging activity (expressed as $\mathrm{IC}_{50}, \mu \mathrm{g} \mathrm{mL}{ }^{-1}$ ) measured in Millo corvo corn flour heated at different temperatures (i.e., 150, 180 and $200{ }^{\circ} \mathrm{C}$ ) for $1 \mathrm{~h}$. The results were compared with those of the unheated flour. Different letters $(a, b)$ indicate differences at $p<0.05$.

Table 2 summarises the contents of individual phenolics (expressed in $\mathrm{g} \mathrm{kg}^{-1}$ ) in Millo corvo flour baked at different temperatures (i.e., 150, 180 and $200^{\circ} \mathrm{C}$ ) for $1 \mathrm{~h}$. From Table 2, the level of all phenolics except trans-ferulic acid decreased significantly $(p<0.05)$ as a result of heating. This decrease suggests a direct correlation between the individual phenolics here determined and those contributing the most to the TPC (Figure 1).

Table 2. Content of individual phenolics in Millo corvo corn flour (expressed in $\mathrm{g} \mathrm{kg}^{-1}$ ) at different heating temperatures.

\begin{tabular}{ccccc}
\hline \multirow{2}{*}{ Phenolics } & \multicolumn{4}{c}{ Millo corvo Flour Samples } \\
\cline { 2 - 5 } & Unheated & $\mathbf{1 5 0}^{\circ} \mathbf{C}$ & $\mathbf{1 8 0}^{\circ} \mathbf{C}$ & $\mathbf{2 0 0}{ }^{\circ} \mathbf{C}$ \\
\hline Chlorogenic acid & $1.17 \pm 0.09^{\mathrm{a}}$ & $0.16 \pm 0.05^{\mathrm{b}}$ & $0.10 \pm 0.03^{\mathrm{b}}$ & $0.13 \pm 0.06^{\mathrm{b}}$ \\
Caffeic acid & $1.43 \pm 0.08^{\mathrm{a}}$ & $0.16 \pm 0.06^{\mathrm{b}}$ & $0.11^{\mathrm{b}} \pm 0.06^{\mathrm{b}}$ & $0.15^{\mathrm{a}} \pm 0.03^{\mathrm{b}}$ \\
Trans-ferulic acid & $0.05 \pm 0.01^{\mathrm{a}}$ & $0.03 \pm 0.08^{\mathrm{a}}$ & $0.05 \pm 0.03^{\mathrm{a}}$ & $0.13 \pm 0.07^{\mathrm{a}}$ \\
Quercetin & $1.77 \pm 0.12^{\mathrm{a}}$ & $0.18 \pm 0.08^{\mathrm{b}}$ & $0.07 \pm 0.03^{\mathrm{b}}$ & $0.16 \pm 0.03^{\mathrm{b}}$ \\
Quercetin-3-glucoside & $0.12 \pm 0.04^{\mathrm{a}}$ & $0.02 \pm 0.05^{\mathrm{b}}$ & $0.03 \pm 0.02^{\mathrm{b}}$ & $0.02 \pm 0.02^{\mathrm{b}}$ \\
Cyanidin-3-O-glucoside & $0.48 \pm 0.03^{\mathrm{a}}$ & $0.18 \pm 0.01^{\mathrm{b}}$ & $0.10 \pm 0.01^{\mathrm{b}}$ & $0.13 \pm 0.02^{\mathrm{b}}$ \\
\hline
\end{tabular}

The values were estimated as mean $\pm \mathrm{SD}(n=3)$. Different letters in the same row indicate differences at $p<0.05$ between baking temperatures.

As seen in Table 2, the decrease in the amount of anthocyanins was noticeable, particularly cyanidin-3-O-glucoside, which dropped from $0.48 \mathrm{~g} \mathrm{~kg}^{-1}$ in the control to $0.18 \mathrm{~g} \mathrm{~kg}^{-1}$ in samples heated at $150{ }^{\circ} \mathrm{C}$. As compared with TAC (Figure 1), the heating effect was more noteworthy for individual anthocyanins than for TAC. In any case, the increase in temperature brought about the thermal degradation of anthocyanins in the studied conditions. As is also observed in Table 2, no significant $(p>0.05)$ differences were found among the temperatures tested. Hence, the individual phenolic content would be similar whatever the temperature applied.

There exist several bibliographic reports describing the direct relationship between the content of colored compounds, such as anthocyanins and carotenoids, and the antioxidant activity of a food $[17,18]$. Since the content of the major anthocyanin, namely, cyanidin3-O-glucoside, decreased significantly with heating, the increase of the DPPH activity (Figure 1) was most likely due to Maillard reaction products being produced as a result of the high temperatures. In fact, the effect of Maillard reactions on the increase of the antioxidant activity has already been reported in cookies [19]. Accordingly, some nonenzymatic browning compounds are capable of stabilising anthocyanins via interaction 
with the resulting aglycone during the thermal degradation process. This is probably also the reason why TAC increased slightly at $200{ }^{\circ} \mathrm{C}$ (Figure 1). However, it is important to bear in mind that Maillard products are regarded as undesirable compounds since their formation involves the destruction of essential amino acids and the production of anti-nutritive compounds [20]. Therefore, baking temperatures higher than $150{ }^{\circ} \mathrm{C}$ are not recommendable. On the other hand, it is also worthy to point out that non-anthocyanin antioxidants, such as carotenoids (e.g., lutein and $\beta$-carotene) and certain non-colored compounds (e.g., ferulic acid), can also contribute to the antioxidant activity [21]. The use of extremely high temperatures might easily degrade these beneficial compounds. Overall, $150{ }^{\circ} \mathrm{C}$ was the selected temperature for the breadmaking process.

\subsection{Comparison between Raw Millo corvo Flour and Millo corvo Bread}

Table 3 represents the TPC and free radical scavenging activity of the homemade Millo corvo bread baked at $150{ }^{\circ} \mathrm{C}$ for $1 \mathrm{~h}$. For comparison, the initial raw Millo corvo flour data are also included in Table 3.

From Table 3, TPC values decreased significantly $(p<0.05)$ from $291.1 \mathrm{mg}$ GAE $100 \mathrm{~g}^{-1}$ in raw flour to $48.1 \mathrm{mg} \mathrm{GAE} 100 \mathrm{~g}^{-1}$ in bread. In contrast, TAC increased significantly $(p<0.05)$ from $381.2 \mathrm{mg} \mathrm{g}^{-1}$ in raw flour to $507.0 \mathrm{mg} \mathrm{g}^{-1}$ in bread, and the antioxidant activity in terms of DPPH was not significantly affected by heating, obtaining statistically insignificant values for raw flour and bread.

Although the effect of $150{ }^{\circ} \mathrm{C}$ on TPC and the DPPH activity in raw flour was similar in both cases, the results of TAC differed considerably (see also Figure 1). In fact, while baking at $150^{\circ} \mathrm{C}$ did not significantly affect TAC in Millo corvo raw flour (Figure 1), it did result in a significant $(p<0.05)$ increase in Millo corvo bread as compared with the unheated

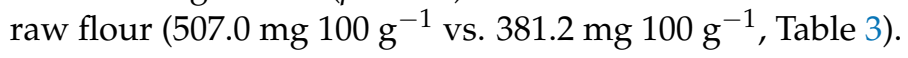

Table 3. TPC (mg GAE $100 \mathrm{~g}^{-1}$ ), TAC (mg cyanidin-3-O-glucoside $100 \mathrm{~g}^{-1}$ ) and DPPH scavenging activity (expressed as $\mathrm{IC}_{50}, \mu \mathrm{g} \mathrm{mL} \mathrm{m}^{-1}$ ) of Millo corvo corn flour mixed with water and homemade Millo corvo corn bread (expressed in $\mathrm{g} \mathrm{kg}^{-1}$ ).

\begin{tabular}{cccc}
\hline Sample & TPC & TAC & IC $_{\mathbf{5 0}}$ \\
\hline Unheated Millo corvo flour & $291.1 \pm 0.08^{\mathrm{a}}$ & $381.2 \pm 0.10^{\mathrm{a}}$ & $1022.2 \pm 0.18^{\mathrm{a}}$ \\
Homemade Millo corvo bread & $48.1 \pm 0.05^{\mathrm{b}}$ & $507.0 \pm 0.13^{\mathrm{b}}$ & $875.3 \pm 0.16^{\mathrm{a}}$ \\
\hline
\end{tabular}

The values were estimated as mean \pm SD $(n=3)$. Different letters in the same row indicate differences at $p<0.05$. Experiments were carried out in triplicate.

Table 4 presents the content of individual phenolics in homemade Millo corvo bread (expressed in $\mathrm{g} \mathrm{kg}^{-1}$ ) baked at $150{ }^{\circ} \mathrm{C}$ for $1 \mathrm{~h}$. In the same way, chlorogenic and caffeic acids, together with quercetin, kept decreasing after baking, whereas ferulic acid was not affected by heating. However, the breadmaking process did minimise the effect of the temperature on the contents of quercetin-3-glucoside and cyanidin-3-O-glucoside. As seen in Table 4, the content of both of them remained the same during the whole baking process. The higher cyanidin-3-O-glucoside content obtained in bread with respect to raw flour was in accordance with the higher TAC above mentioned (see Table 3). This indicates that the thermal degradation of anthocyanins was lower during the baking of the bread than during the heating of the raw flour. This was most likely due to the mildness of the temperature reached through the addition of water, whose efficiency was sufficient to avoid the thermal degradation of the most labile phenolics.

Finally, the statistical comparison between the free radical scavenging activity in terms of the DPPH of raw flour (i.e., $\mathrm{IC}_{50}$ value of $1022.2 \mu \mathrm{g} \mathrm{mL}^{-1}$ ) and the final bread (i.e., $\mathrm{IC}_{50}$ value of $875.3 \mu \mathrm{g} \mathrm{mL}^{-1}$, Table 3) indicates that the DPPH activity was not significantly affected either by the temperature or the presence of water. With a view to verifying this aspect, a PCL assay was also applied to the final Millo corvo bread. The value obtained was $916.19 \mathrm{ng}$ eq Trolox $\mu \mathrm{L}^{-1}$, which was statistically similar to that of Millo corvo raw flour (i.e., 734.3 ng equivalents Trolox $\mu \mathrm{L}^{-1}$, Table 1). The PCL results support those of the DPPH assay. Therefore, the preservation of the antioxidant activity of the starting raw 
Millo Corvo flour in the final bread baked from it in the baking conditions applied here was confirmed.

Table 4. Content of individual phenolics in unheated raw Millo corvo corn flour and homemade Millo corvo corn bread (expressed in $\mathrm{g} \mathrm{kg}^{-1}$ ).

\begin{tabular}{ccc}
\hline \multirow{2}{*}{ Phenolics } & \multicolumn{2}{c}{ Millo corvo Flour Samples } \\
\cline { 2 - 3 } & Unheated Millo corvo Flour & Home-made Millo corvo Bread \\
\hline Chlorogenic acid & $1.17 \pm 0.06^{\mathrm{a}}$ & $0.08 \pm 0.01^{\mathrm{a}}$ \\
Caffeic acid & $1.43 \pm 0.02^{\mathrm{a}}$ & $0.08 \pm 0.02^{\mathrm{b}}$ \\
Trans-ferulic acid & $0.12 \pm 0.01^{\mathrm{a}}$ & $0.10 \pm 0.02^{\mathrm{a}}$ \\
Quercetin & $1.77 \pm 0.03^{\mathrm{a}}$ & $0.07 \pm 0.01^{\mathrm{b}}$ \\
Quercetin-3-glucoside & $0.09 \pm 0.01^{\mathrm{a}}$ & $0.08 \pm 0.01^{\mathrm{a}}$ \\
Cyanidin-3-O-glucoside & $0.48 \pm 0.04^{\mathrm{a}}$ & $0.32 \pm 0.01^{\mathrm{a}}$ \\
\hline
\end{tabular}

The values were estimated as mean \pm SD $(n=3)$. Different letters in the same row indicate differences at $p<0.05$ between baking temperatures.

To our knowledge, there is no bibliographic report on the antioxidant properties of Millo corvo corn bread. This is why our results cannot be contrasted with the literature. However, the influence of baking on anthocyanins in colored-grain wheat bread was recently studied $[22,23]$. These authors also conclude that baking does not significantly affect the anthocyanin content; hence, colored wheat genotypes are also adequate for bread production.

\section{Conclusions}

The present study demonstrated that Millo corvo corn bread possessed the same phenolic content and antioxidant activity as the starting flour as long as $150{ }^{\circ} \mathrm{C}$ was applied during the baking process. This indicates that Millo corvo is a suitable corn variety for bread production due to the remaining antioxidant content after baking. Our objective now is to extend these results to the study of other colored compounds and additional bakery products. In particular, the consideration of carotenoids and additional anthocyanins and the study of new parameters, such as the baking time and the addition of citric acid, are scheduled.

Author Contributions: Conceptualisation, G.P.B.; methodology, G.P.B. and M.L.R.d.C.; formal analysis, G.P.B. and M.L.R.d.C.; investigation, G.P.B. and M.L.R.d.C.; data interpretation, G.P.B. and M.L.R.d.C., bibliographic search, G.P.B. and M.L.R.d.C., writing and review, M.L.R.d.C. All authors have read and agreed to the published version of the manuscript.

Funding: This work was supported by the Comunidad of Madrid and European funding from FSE and FEDER programs (project S2018/BAA-4393, AVANSECAL-II-CM).

Acknowledgments: We are grateful to Asociacion Cultural Meiro (Morrazo, Pontevedra, Spain) for the Millo Corvo flour samples supplied and the Analysis Service Unit facilities of ICTAN for the spectroscopy analysis.

Conflicts of Interest: The authors declare no conflict of interest.

\section{References}

1. Zilic, S.; Serpen, A.; Akillioglui, G.; Gökmen, V.; Vancetovic, J. Phenolic Compounds, Carotenoids, Anthocyanins, and Antioxidant Capacity of Colored Maize (Zea mays L.) Kernels. J. Agric. Food Chem. 2012, 60, 1224-1231. [CrossRef] [PubMed]

2. Pascual-Teresa, S.; Santos-Buelga, C.; Rivas-Gonzalo, J.C. LC-MS analysis of anthocyanins from purple corn cob. J. Sci. Food Agric. 2002, 82, 1003-1006. [CrossRef]

3. Kähkönen, M.P.; Heinonen, M. Antioxidant activity of anthocyanins and their aglycons. J. Agric. Food Chem. 2003, 51, 628-633. [CrossRef] [PubMed]

4. Aoki, H.; Kuze, N.; Kato, Y. Anthocyanins Isolated from Purple Corn (Zea mays L.). 2001. Available online: http: //www.ffcr.or.jp/zaidan/FFCHROME.nsf/7bd44c20b0dc56264925602001b65e9/c6698773361b42b249256ba60018e581/SFILE/ anthocyanin-FFIJ199.pdf (accessed on 1 April 2021).

5. Adom, K.K.; Liu, R.H. Antioxidant activity of grains. J. Agric. Food Chem. 2002, 50, 6182-6187. [CrossRef] 
6. Cronin, K.; Preis, C. A statistical ana-lysis of biscuit physical properties as affected by baking. J. Food Eng. 2000, 46, 217-225. [CrossRef]

7. Sablani, S.S.; Marcotte, M.; Baik, O.D.; Castaigne, F. Modeling of simultaneous heat and water transport in the baking process. Lebensm Wiss Technol. 1998, 31, 201-209. [CrossRef]

8. Giusti, M.M.; Wrolstad, R.E. Acylated anthocyanins from edible sources and their application in food systems. Biochem. Eng. J. 2003, 14, 217-225. [CrossRef]

9. Singleton, V.L.; Rossi, J.A.; Menon, V.P. Colorimetry of total phenolics with phosphomolybdic-phosphotungstic acid reagents. Am. J. Enol. Viticult. 1965, 16, 144-158.

10. Giusti, M.; Wrolstad, R.E. Characterization and Measurement of Anthocyanins by UV Visible Spectroscopy. In Current Protocols in Food Analytical Chemistry; Giusti, M.M., Wrolstad, R.E., Eds.; Wiley: New York, NY, USA, 2001; p. 1.

11. Smith, R.C.; Reeves, J.C.; Dage, R.C.; Schnettler, R.A. Antioxidant properties of 2-imidazolones and 2-imidazolthiones. Biochem. Pharmacol. J. 1987, 36, 1457-1460. [CrossRef]

12. Besco, E.; Braccioli, E.; Vertuani, S.; Ziosi, P.; Brazzo, F.; Bruni, R.; Sacchetti, G.; Manfredini, S. The use of photochemiluminescence for the measurement of the integral antioxidant capacity of baobab products. Food Chem. 2007, 102, 1352-1356. [CrossRef]

13. Wesołowska, M.; Dżugan, M. The Use of the Photochem Device in Evaluation of Antioxidant Activity of Polish Honey. Food Anal. Methods 2017, 10, 1568-1574. [CrossRef]

14. Blanch, G.P.; Gómez-Jiménez, M.C.; Ruiz del Castillo, M.L. Exogenous salicylic acid improves phenolic content and antioxidant activity in table grapes. Plant Food Hum. Nutrit. 2020, 75, 177-183. [CrossRef]

15. Dżugan, M.; Kisała, J. Application of the Photochem System in Agricultural Investigations. In Modern Methods in Analysis of Agricultural Raw Materials; Puchalski, C., Bartosz, G., Eds.; University of Rzeszow Publishing Office: Rzeszów, Poland, 2011; pp. 193-203.

16. Del Pozo-Insfran, D.; Brenes, C.H.; Saldivar, S.O.S.; Talcott, S.T. Polyphenolic and antioxidant content of white and blue corn (Zea mays L.) products. Food Res. Intern. 2006, 39, 696-703. [CrossRef]

17. López-Martínez, L.X.; Oliart-Ros, R.M.; Valerio-Alfaro, G.; Lee, C.-H.; Parkin, K.L.; García, H.S. Antioxidant capacity, phenolic compounds and anthocyanins content of eighteen strains of Mexican maize. LWT-Food Sci. Tecnhol. 2009, 42, 1187-1192. [CrossRef]

18. Rodríguez, V.M.; Soengas, P.; Landa, A.; Ordás, A.; Revilla, P. Effects of selection for color intensity on antioxidant capacity in maize (Zea mays L.). Euphytica 2013, 193, 339-345. [CrossRef]

19. Zilic, S.; Kocadagli, T.; Vancetovic, J.; Gökmen, V. Effects of baking conditions and dough formualtions on phenolic compounds stability, antioxidant capacity and color of cookies made from anthocyanin-rich corn flour. LWT-Food Sci. Technol. 2016, 65, 597-603. [CrossRef]

20. Jaeger, H.; Janositz, A.; Knorr, D. The Maillard reaction and its control during food processing. The potential of emerging technologies. Pathol. Biol. 2010, 58, 207-213. [CrossRef] [PubMed]

21. Srinivason, M.; Sudheer, A.R. Ferulic acid: Therapeutic potential through its antioxidant activity. J. Clin. Biochem. Nutr. 2007, 40, 92-100. [CrossRef] [PubMed]

22. Eliasova, M.; Kotikova, Z.; Lachman, J.; Orsak, M.; Martinek, P. Influence of baking on anthocyanin content in coloured-grain wheat bread. Plant Soil Environ. 2020, 66, 381-386. [CrossRef]

23. Bartl, P.; Albreth, A.; Skrt, M.; Tremlova, B.; Ostadalova, M.; Smejkal, K.; Vovk, I.; Ulrich, N.P. Anthocyianins in purple and blue wheat grains and in resulting bread: Quantity, composition, and thermal stability. Int. J. Food. Sci. Nutr. 2015, 66, 514-519. [CrossRef] [PubMed] 